
\title{
$\begin{array}{ll}\text { Research Square } & \begin{array}{l}\text { Preprints are preliminary reports that have not undergone peer review. } \\ \text { They should not be considered conclusive, used to inform clinical practice, } \\ \text { or referenced by the media as validated information. }\end{array}\end{array}$
}

\section{A New Approach in DENV Diagnostic based on Linear Peptides Obtained by Phage Display}

Mirna Burciaga-Flores

Medical and Pharmaceutical Biotechnology Unit. Center for Research and Assistance in Technology and Design of the State of Jalisco (CIATEJ)

\section{Tanya A. Camacho-Villegas}

CONACYT - Medical and Pharmaceutical Biotechnology Unit. Center for Research and Assistance in Technology and Design of the State of Jalisco (CIATEJ)

Pavel H. Lugo-Fabres

CONACYT - Medical and Pharmaceutical Biotechnology Unit. Center for Research and Assistance in Technology and Design of the State of Jalisco (CIATEJ)

\section{Abel Gutiérrez-Ortega}

Medical and Pharmaceutical Biotechnology Unit. Center for Research and Assistance in Technology and Design of the State of Jalisco (CIATEJ)

\section{José Esteban Muñoz-Medina}

Central Laboratory of Epidemiology, Mexican Institute of Social Security (Centro Médico Nacional La Raza)

Darwin E. Elizondo-Quiroga ( $\square$ delizondo@ciatej.mx)

Medical and Pharmaceutical Biotechnology Unit. Center for Research and Assistance in Technology and Design of the State of Jalisco (CIATEJ)

\section{Research Article}

Keywords: Dengue, Zika , Chikungunya viruses, IgG , IgM

Posted Date: February 5th, 2021

DOI: https://doi.org/10.21203/rs.3.rs-155529/v1

License: @ (1) This work is licensed under a Creative Commons Attribution 4.0 International License. Read Full License 


\section{Abstract}

Dengue is a viral disease caused by any of the four distinct dengue virus (DENV) serotypes that circulate in many parts of the world. DENV now co-circulates with Zika and Chikungunya viruses (ZIKV and CHIKV) in many regions of the Americas. Having this in mind, plus the fact that DENV clinical diagnosis persists as a difficult task, due to the similarity in symptoms, as well as false-positive results by the crossreactivity of the IgG and IgM against these three viruses, correct identification of DENV at an early stage of the disease is essential to minimise transmission and prevent potentially devastating sequelae. Here, by phage display, we isolate specific peptides for dengue virus NS1 protein. The specificity of the linear peptides as diagnostic tools for DENV NS1 protein in sera samples was investigated, and the selected peptides showed the ability to recognise DENV, and no cross-reactivity was shown. Moreover, in silico analysis was performed to assess the possible binding modes of these peptides to DENV-NS1, using a molecular docking approach. These peptides are suitable for use in an ELISA assay for dengue virus detection in human serum and the possibility to adapt these peptides to PoC platforms.

\section{Introduction}

Dengue virus (DENV) is endemic in more than 100 countries in Asia, America, Africa, and the Caribbean ${ }^{1}$, in such a way that the World Health Organization (WHO) has classified it as one of the arthropod-borne viruses (arboviruses) with the highest prevalence in the world ${ }^{2}$. Previous reports indicated that there are four different serotypes of this virus (DENV 1-4). These viruses belong to the flavivirus genus, which also includes Zika (ZIKV), Yellow Fever (YF), and West Nile viruses (WNV) ${ }^{3}$. Infection caused by DENV can be asymptomatic; however, the symptoms classification is: 1) Undifferentiated Fever (UF), 2) Dengue Fever (DF), 3) Dengue Haemorrhagic Fever (DHF), 4) Dengue Shock Syndrome (DSS), 5) Expanded Dengue Syndrome (EDS) and 6) Unusual Dengue (UD) ${ }^{4}$. Severe cases of DENV cause DHF or DSS (generally associated with a secondary DENV infection), resulting in approximately 22,000 deaths per year globally, mainly affecting children ${ }^{5}$. The characteristic of the infection course presents three stages: 1) febrile (1-7 days from symptom onset), 2) critical (from days 8-9), and 3) recovery (after day 10). The symptoms developed are fever, headache, retro-ocular pain, myalgia, arthralgia, dehydration, vomiting, lethargy, abdominal pain, loss of appetite (anorexia), and skin eruptions (rash) ${ }^{6,7}$.

Likewise, the presence of leukopenia and thrombocytopenia has been widely reported ${ }^{8}$. Due to its complex nature and the cocirculation of ZIKV or chikungunya virus (CHIKV) in the same endemic area, it is not easy to obtain the correct diagnosis. Different viral markers can be detected at different stages of infection. However, early identification of the virus is pivotal in disease management. Usually, DENV diagnosis considers the clinical symptoms which are confirmed through laboratory analysis. The diagnostic method to be applied depends on the stage of infection; during symptoms, direct methods are carried out: viral isolation, detection of the viral genome (RT-PCR) or viral antigens (NS1 mainly), or a combination of these. Non-structural protein 1 (NS1) is an early marker of infection and its detection in serum matches with detectable viremia $^{9-11}$. In the critical stage of recovery, serological tests are implemented for the detection of $\operatorname{lgM}$ and $\lg \mathrm{G}^{12}$. Several research groups have developed different diagnostic methods, (Table 1) with a tendency for Point of Care (PoC), using different biological matrices at the early stage of the infection. 
Table 1

Update of DENV diagnostic strategies.

\begin{tabular}{|c|c|c|c|c|c|c|c|c|}
\hline Detection technique & $\begin{array}{l}\text { Limit of } \\
\text { Detection } \\
\text { (LOD) }\end{array}$ & $\begin{array}{l}\text { Biological } \\
\text { Matrix }\end{array}$ & $\begin{array}{l}\text { Sample } \\
\text { volume } \\
\text { required }\end{array}$ & $\begin{array}{l}\text { Sample } \\
\text { treatment }\end{array}$ & $\begin{array}{l}\text { Molecular } \\
\text { target }\end{array}$ & Rehearsal & $\begin{array}{l}\text { Qualitative } \\
\text { or } \\
\text { Quantitative }\end{array}$ & Reference \\
\hline LFA & $\begin{array}{l}5-600 \\
\mathrm{ng} / \mathrm{mL}\end{array}$ & Serum & $40 \mu \mathrm{L}$ & Centrifugation & NS1 & $\begin{array}{l}\text { Does not } \\
\text { specify }\end{array}$ & Quantitative & 39 \\
\hline SAM/NH2rGO/ PAMAM & $\begin{array}{l}0.08 \mathrm{pM} \\
\text { to } 0.5 \mathrm{pM} .\end{array}$ & $\begin{array}{l}\text { Not } \\
\text { evaluated }\end{array}$ & $\begin{array}{l}\text { Does } \\
\text { not } \\
\text { specify }\end{array}$ & - & $\begin{array}{l}\text { E protein } \\
\text { of DENV- } \\
2\end{array}$ & $10 \min$ & Quantitative & 40 \\
\hline \multirow[t]{5}{*}{ QDs-LSPR } & $\begin{array}{l}24.6 \mathrm{fM} \\
\text { DENV-1 }\end{array}$ & \multirow[t]{5}{*}{$\begin{array}{l}\text { Not } \\
\text { evaluated }\end{array}$} & \multirow[t]{5}{*}{$100 \mu \mathrm{L}$} & \multirow[t]{5}{*}{$\begin{array}{l}\text { RNA } \\
\text { extraction }\end{array}$} & \multirow[t]{5}{*}{$\begin{array}{l}\text { Does not } \\
\text { specify }\end{array}$} & \multirow[t]{5}{*}{$\begin{array}{l}\text { Does not } \\
\text { specify }\end{array}$} & \multirow[t]{5}{*}{ Qualitative } & \multirow{5}{*}{41} \\
\hline & $11.4 \mathrm{fM}$ & & & & & & & \\
\hline & DENV-2 & & & & & & & \\
\hline & $\begin{array}{l}39.8 \mathrm{fM} \\
\text { DENV-3 }\end{array}$ & & & & & & & \\
\hline & $\begin{array}{l}39.7 \mathrm{fM} \\
\text { DENV-3 }\end{array}$ & & & & & & & \\
\hline \multirow[t]{2}{*}{ RT-PCR } & $\begin{array}{l}1 \times 10^{4} \\
\text { genome }\end{array}$ & Blood & \multirow[t]{2}{*}{$250 \mu \mathrm{L}$} & Non & 3'-UTR & $\nabla 2 \mathrm{~h}$ & Qualitative & \multirow[b]{2}{*}{42} \\
\hline & $\begin{array}{l}\text { copies } \\
\text { eq/mL }\end{array}$ & Plasma & & \multicolumn{2}{|l|}{ Centrifugation } & & & \\
\hline LFA & $\begin{array}{l}4.8 \\
\mathrm{ng} / \mathrm{mL}\end{array}$ & Serum & $150 \mu \mathrm{L}$ & Centrifugation & NS1 & $10 \min$ & Quantitative & 43 \\
\hline RT-LAMP & $\begin{array}{l}\sim 1.22 \\
\text { UFP eq }\end{array}$ & $\begin{array}{l}\text { Urine, } \\
\text { plasma, } \\
\text { mosquitoes }\end{array}$ & $5 \mu \mathrm{L}$ & - & $\begin{array}{l}\text { Does not } \\
\text { specify }\end{array}$ & $\begin{array}{l}20-40 \\
\min \end{array}$ & Qualitative & 44 \\
\hline Immunochromatography & * & Serum & $30 \mu \mathrm{L}$ & Centrifugation & $\begin{array}{l}\text { NS1 of } \\
\text { DENV or } \\
\text { ZIKV }\end{array}$ & $\begin{array}{l}15-60 \\
\min \end{array}$ & Qualitative & 45 \\
\hline SPGE-ELFI & $\begin{array}{l}0.5 \\
\mathrm{ng} / \mathrm{mL}\end{array}$ & NS1 in PBS & $50 \mu \mathrm{L}$ & - & NS1 & $30 \mathrm{~min}$ & Quantitative & 46 \\
\hline \multirow[t]{2}{*}{$\begin{array}{l}\text { Amine modified Gold } \\
\text { Chip (NHS/EDC) }\end{array}$} & \multirow[t]{2}{*}{$\begin{array}{l}2 \times 10^{5} \\
\text { UFP/mL }\end{array}$} & \multirow[t]{2}{*}{$\begin{array}{l}\text { Antigen in } \\
\text { PBS }\end{array}$} & \multirow[t]{2}{*}{$6 \mu \mathrm{L}$} & \multirow[t]{2}{*}{-} & $\begin{array}{l}\text { Antigen } \\
\text { of }\end{array}$ & $10 \mathrm{~min}$ & Quantitative & \multirow[t]{2}{*}{47} \\
\hline & & & & & DENV-2 & & & \\
\hline \multirow[t]{2}{*}{ Impedimetric biosensor } & $3 \mathrm{ng} / \mathrm{mL}$ & NS1 in PBS & \multirow[t]{2}{*}{$50 \mu \mathrm{L}$} & - & NS1 & $30 \mathrm{~min}$ & Quantitative & 48 \\
\hline & 30 ng/mL & Serum & & \multicolumn{2}{|l|}{ Centrifugation } & & & \\
\hline SRP biosensor & $\begin{array}{l}\text { Sensitivity } \\
=83-93 \% \\
\text { specificity } \\
=100 \%\end{array}$ & Serum & $1 \mu \mathrm{L}$ & Centrifugation & $\begin{array}{l}\text { NS1 of } \\
\text { DENV- } \\
1,2,3,4\end{array}$ & $10 \mathrm{~min}$ & Qualitative & 49 \\
\hline \multicolumn{9}{|c|}{$\begin{array}{l}\text { Notes: a) LFA: Lateral Flow assay, b) SAM/NH2rGO/PAMAM: SPR sensor based on self-assembled monolayer/reduced graphene oxide- } \\
\text { polyamidoamine dendrimer, c) RT-LAMP: Reverse Transcription Loop-mediated Isothermal Amplification, d) QDs-LSPR: Quantum dots- } \\
\text { Localized Surface Resonance Plasmon, e) SPGE-ELFI: Electrochemical Lateral Flow-Screen printed Gold electrodes, f) SRP: Surface } \\
\text { Plasmon Resonance. * Depends on the combination of mAbs, see full text. }\end{array}$} \\
\hline
\end{tabular}

Considering that dengue is present in developing tropical countries where other arboviruses cocirculate frequently ${ }^{13}$, newer diagnostic platforms are now looking for simplicity to reduce the assay costs and time to obtain readout. For the development of serological tests, specific capture and detection elements are crucial to detect the viral antigen. Conventional antibodies, such as polyclonal (pAb) and monoclonal (mAbs), have been highly explored for this purpose in the last decades ${ }^{14}$. Different formats of $m A b s$ have been evaluated for diagnosis applications: human naive antibodies, even some smaller antibody formats such as variable domain heavy-chain antibodies $(\mathrm{VHH})^{15}$, single variable new antigen receptor domain antibody fragments (vNAR) ${ }^{16,17}$ or single-chain fragments variable (scFv) ${ }^{18}$. However, an important factor is the time and cost of large-scale production and purification processes of these antibodies. Another approach uses peptide- 
display phages as an alternative for the detection of viral diseases ${ }^{19}$. Peptide-display phages present some advantages: can be easily synthesised and their use can reduce the complexity of the development of platforms such as lateral flow assays or biosensor approaches, due to the ease coupled to nanoparticles or biomolecules ${ }^{20,21}$. The improvement of the DENV detection test, especially in the early stage of illness, it is essential to generate peptides or antibodies with no cross-reaction with other arboviruses. The flavivirus NS1 protein is a useful infection marker because its accumulation in dengue patients' sera can be found at concentrations up to $50 \mu \mathrm{g} / \mathrm{ml}$ in the febrile stage of illness $^{22}$. The work presented herein aimed to isolate and characterise linear peptides that bind to the NS1 protein of DENV without crossreactivity with ZIKV and CHIKV using serum samples. As proof of concept, we evaluated an ELISA for NS1 detection in the illness's febrile stage. As a perspective, it can be used for the development of a PoC.

\section{Results}

\section{- Identification of DENV NS1-binding linear peptides.}

A phage library displaying linear peptides of 20 amino acids was challenged for binding to DENV-NS1 protein. In the first round of selection, we obtained $2.0 \times 10^{6}$ phage particles with a title increase in the second and third rounds with $4.0 \times 10^{9}$ and $5.0 \times 10^{9}$, respectively (Figure 1 ). After three selection rounds, fifteen phage clones were selected for sequencing. Plasmids containing no sequence or repeated sequences were discarded. The sequences of the selected peptides are shown in Table 2. A total of six phages displaying linear peptides were isolated, and ELISA results suggested that three of these linear peptides clones denominated NS1P3, NS1P6, and NS1P8 (Figure 2A, Figure 2C, Figure 2D) were specific against DENV-rNS1 as compared to BSA (negative control) with a statistically significant difference ( $p=0.0002, p=0.0002$, and $\mathrm{p}<0.0001$, respectively). The commercial antibody used as a positive control had no difference between recognizing rNS1 protein and BSA. These results suggest that the phage clones NS1P3, NS1P6, and NS1P8 are specific for rNS1. The batch production of these clones was used to evaluate the recognition ability of viruses present in serum samples. The remaining three phage clones (NS1P4, NS1P9, NS1P14) were not specific for rNS1 protein (Figure 2B, Figure 2E, Figure 2F). These phage clones were discarded for this study and stored for further evaluations.

\section{- Linear peptides can bind to NS1 proteins from all four DENV serotype in serum.}

The DENV serotype specificity using the peptide-display phages (NS1P3, NS1P6, and NS1P8) was evaluated in an ELISA sandwich, using sera samples of the four serotypes of DENV. The results revealed the binding affinity of the peptide-display phages against the four serotypes of DENV, where the phage clone NS1P3 (Figure 3A) and NS1P6 (Figure 3B) shows a statistically significant difference ( $<<0.0001, p<0.0001$ and, $p=0.0208$, respectively) compared to the negative serum control. The same result is found in recognition of the DENV-2, DENV-3, and DENV-4 serotypes, respectively. However, in the NS1P8 (Figure 3C), no statistically significant difference ( $p<0.05)$ was found to recognise DENV-3, and DENV-4 serotypes present in serum, compared to the negative serum control. These results indicated that NS1P3, NS1P6, and NS1P8 showed DENV recognition in general, but they do not show serotype specificity. However, the recognition of the DENV present in serum is relevant, suggesting all three peptide-display phages were reactive to the hexameric isoform of the NS1 protein.

\section{- Linear peptides anti-NS1 have no cross-reactivity with other arboviruses.}

Since DENV is phylogenetically related to ZIKV, NS1 protein shares high homology in amino acid sequences; therefore, the selected peptidedisplay phages were tested to recognise native ZIKV NS1 by ELISA assay, using serum samples. We also tested our phage clones against CHIKV serum samples to assure no cross-reactivity. Phage clones NS1P3 (Figure 4A), NS1P6 (Figure 4B), and NS1P8 (Figure 4C) have a statistically significant difference ( $p$ values are shown on each graph) among the recognition of the DENV present in serum samples versus ZIKV or CHIKV present in positive serums. The result suggests that NS1P3, NS1P6, and NS1P8 did not cross-react with another phylogenetically related arbovirus, such as ZIKV and a non-related arbovirus, like CHIKV and, these peptide-display phages can be used in a detection platform for the recognition of DENV in complex samples.

\section{- Molecular docking}

The results of GalaxyPepDock simulations presented herein indicated that our peptides bind to DENV-NS1 protein, as shown in Figure 5. The interactions between DENV-NS1 protein and our peptides were analysed using contact maps derived from the CABS-Dock simulations. Figure 5 shows the data from the contact maps with a cut-off distance of $3 \AA$, suggesting that twelve DENV-NS1 residues are involved in the binding to NS1P3 peptide (Figure 5A): Leu318, Lys211, Asn207, Cys316, Val287, Phe277, Glu205, Ser315, Pro258, Leu212, Glu289, and Tyr256. Eight DENV-NS1 residues form the binding site with NS1P6 peptide (Figure 5B): Asn293, Asn234, Ser351, Thr264, Lys347, Glu238, Lys227, and 
Glu208. Fourteen DENV-NS1 residues form that the binding site with NS1P8 peptide (Figure 5C): Arg294, Ile246, Asn234, Ile224, Asn293, Lys245, Lys227, Trp232, Arg336, Cys291, Val236, Trp225, Thr222, and Thr209. The root means square deviation of peptide coordinates after superposition of receptor molecules (RMSD) were 1.94601, 1.95461, and 3.90322, NS1P3, NS1P6, and NS1P8, respectively.

\section{Discussion}

The linear peptides specific for DENV-NS1 were selected by phage display using rNS1 protein-coated as the capture antigen. During panning progression against NS1 protein, the amounts of eluted phages increase stepwise as expected (Figure 1). From the panning experiment, we isolated three individual phage clones from the third round of selection that were designated as NS1P3, NS1P6, and NS1P8. All these three phage clones bind to rNS1. The phage display technique has been extensively used by several authors to search for interacting peptides against different targets, for example, de la Guardia et al. (2017) ${ }^{23}$. They used a 7-mer peptide library targeting the full envelope or domain III from DENV-2. Chew et al. (2015) used 12-mer peptide library targeting the full DENV-2 virion ${ }^{24}$, and Panya et al. (2014), targeted the hydrophobic envelope pocket ${ }^{25}$. Our peptides do not share homology with the peptides founded by these three authors, even though results may not be comparable as distinct libraries and targets were used. However, these findings suggest that small peptides (7-20 amino acids) can bind to a big target as NS1 protein (45-55 kDa) (Figure 2), or even a full DENV virion, and it can be used to block the infectivity of the virus or as detection element for diagnosis applications, as in our case. On the other hand, the monoclonal antibody used as positive control showed a colorimetric reaction when challenged versus rNS1. However, it does not show a statistically significant difference ( $p<0.001)$ compared to the negative control.

Owing to the phylogenetic relationship among dengue viruses, NS1 protein from all serotypes share $69-80 \%$ of identity, therefore we expected a cross-reactivity among the four serotypes since we did not make a subtractive biopanning as Lebani et al. (2017) ${ }^{3}$. Nevertheless, an important aspect is that the native NS1 protein of the four DENV serotypes can be detected by our peptide-display phages in a complex matrix as serum samples (Figure 3), even when peptides are small. Our results are consistent with those obtained by (Figure 3 ) were the phage clones have a statistically significant difference $(\mathrm{p}<0.0001)$ between the recognition of DENV-NS1 and the negative serum control.

Recent studies like the reported by Andreata et al. (2020) emphasize the relevance of the specificity of serological tests based on NS1 detection; they analysed commercial kits designed to detect DENV-NS ${ }^{27}$. Their finding revealed that $33 \%$ of these commercial kits reacted with ZIKV-NS1 present in supernatants of cell culture. It is well-known that arboviruses may cross-react in the immunodiagnostic tests due to their phylogenetic relationship and antigenic similarities ${ }^{28}$. However, it can be noted that NS1P3, NS1P6, and NS1P8 specifically bound to DENV-NS1 in the ELISA sandwich (Figure 4), and not to other arboviruses (ZIKV, CHIKV), which represents an advantage over other publications based on the use of mAbs for the detection of NS1, such as Rocha et al. (2017) who generated four monoclonal antibodies against the NS1 of dengue virus serotype 2, and two of them did cross-react to ZIKV ${ }^{29}$. Thus, these preliminary results indicate that the phage-displayed peptides, like NS1P3, NS1P6, and NS1P8, could be particularly useful for developing a PoC test that minimizes the risks associated with false-positive results among ZIKV and/or CHIKV-infected subjects. As a perspective, the linear peptide can be evaluated for the same purpose.

Analysis of the contact map indicates that our novel peptides can bind to similar regions of DENV-NS1 located between 205 and 336 residues. In this sense, a sandwich of two of these peptides (NS1P6-NS1P8) for DENV-NS1 detection cannot be an option.

The Omokoko et al. (2014) group reports molecular docking results that suggest potential epitopes highly conserved in a region flanked by amino acids 221 and 266 of DENV-NS1 ${ }^{30}$, as a relevant epitope region present in DENV infected patients. The linear peptides isolated by our group have potential applications such as antiviral agents. This hypothesis needs to be explored in the future, as a recent report by Songprakhon et al. (2020), where DENV-NS1 was recommended and explored as a molecular target for reducing infectious virus production in cell culture; several peptides of 12 amino acids were able to bind to DENV-NS1 and shows a decrease in the DENV infectious production, making the NS1 protein a promising molecular target for drug design ${ }^{31}$.

Many research groups have reported the use of different formats of antibodies as mAb, VHH, scFv, and Fab for the detection of one or more serotypes of DENV3,15,26,32-34 however, they inevitably resort to the production of antibodies by recombinant expression in cellular systems, increasing the cost of the production and downstream procedures, as purification and refolding if necessary. Instead, our peptides are a cheaper alternative and easy to synthesise. Our results provide the proof of concept for developing a diagnostic test using peptide-display phages as elements for the capture of DENV-NS1. Nevertheless, an essential limitation of this study is that NS1 concentration in the serum samples is not known; therefore, it requires additional validation. Future evaluation of the established assays will involve more massive sets of a case-control study.

In conclusion, we generated three peptide-displaying phages against the DENV-NS1 protein. Our three peptide-displaying phages named NS1P3, NS1P6, and NS1P8 recognised all serotypes of DENV by ELISA and did not cross-react to ZIKV and CHIKV in serum samples. Thus, the selection and characterisation of the peptides, the prediction of potential epitopes, and the specificity of anti-DENV NS1 peptides may

Page 5/13 
contribute to the development of diagnostic tools as LFA, ELISA, peptide-based biosensors or, another immunoassay formats able to differentiate DENV, ZIKV, or CHIKV infections. Due to the current situation caused by SARS-Cov2, it is crucial to consider this virus. Although it is not phylogenetically related to DENV, ZIKV, and CHIKV, it can also cause similar symptoms in the disease's initial stages. In this sense, it would be interesting to develop a PoC test to detect and differentiate among all these viruses simultaneously.

\section{Methods}

\section{- Bio panning from peptide library.}

The TriCo-20 peptide library (Creative Biolabs) was panned against recombinant protein NS1 (rNS1). The bio panning was done using procedures previously described by the manufacturer. Three rounds of subtracted panning were performed. The rNS1 (Fitzgerald, $80 \mathrm{R}-4280$ ) was adsorbed onto a 96-well plate at $2.5 \mu \mathrm{g} / \mathrm{mL}$; next, wells were blocked with blocking buffer $(0.1 \mathrm{M} \mathrm{NaHCO} 3(\mathrm{pH} 8.6), 5 \mathrm{mg} / \mathrm{mL} \mathrm{BSA}, 0.02 \%$ $\mathrm{NaN}_{3}, 0.1 \mu \mathrm{g} / \mathrm{mL}$ streptavidin). The library of phages displaying linear peptides ( $\left.2 \times 10^{11} \mathrm{PFU}\right)$ in $100 \mu \mathrm{L}$ of blocking buffer, were added to the blocked wells where no rNS1 was adsorbed, and incubated for $1 \mathrm{~h}$ at $37^{\circ} \mathrm{C}$. Next the non-bound phages were transferred to the wells where rNS1 was immobilized, and incubated for $1 \mathrm{~h}$ at $37^{\circ} \mathrm{C}$. Subsequently, 10 washes were performed using PBS with $0.05 \%$ Tween 20 (PBS-T). The bound phages were eluted from the plate and used to infect E. coli ER2738 cells for 15 min at room temperature without shaking. These infected cells were used to amplify the selected phages. The amplified phages were used in the next round of panning, and the titration of the precipitated phages was performed.

\section{- Screening by sequencing.}

After 3 rounds of selection, 15 individual phage clones were amplified, and from them, the M13KE plasmid was extracted according to Zymoß Miniprep kit instructions (Zymo Research). Sequencing was performed by customer service (LANBAMA-IPICYT) using the -96 pIII sequencing primer (5'-CCC TCA TAG TTA GCG TAA CG-3'). Then the sequences were analysed according to the TriCo-20 library manual. Moreover, the phage-displayed peptide sequences were translated with the ExPASy Proteomics Server ${ }^{35}$ Primary structure and theoretical properties were predicted with the Pepdraw platform ${ }^{36}$.

\section{- Direct Enzyme Linked Immunosorbent Assay (ELISA).}

Fifteen randomly selected phage clones were cultured in a $2 \mathrm{TY}$ medium containing $10 \mu \mathrm{g} / \mathrm{mL}$ tetracycline, and the resulting phages were precipitated with $20 \%$ PEG 8,000 in $2.5 \mathrm{M} \mathrm{NaCl}$ and resuspended in PBS according to the manufacturer's protocol (Creative Biolabs). An enzyme-linked immunosorbent assay (ELISA) was performed to verify the specificity of each clone. Briefly, $50 \mu \mathrm{L}$ of the rNS1 at $2 \mu \mathrm{g} / \mathrm{mL}$ in PBS was coated on a 96 well plate overnight at $4^{\circ} \mathrm{C}$. The unbound protein was discarded. The plate was blocked using $100 \mu \mathrm{L}$ of $3 \% \mathrm{BSA}$ in PBS for two hours at $37^{\circ} \mathrm{C}$. The blocking buffer was discarded. Afterwards, $50 \mu \mathrm{L}$ of monoclonal antibody anti-NS1 at $1 \mu \mathrm{g} / \mathrm{mL}$ (My BioSource, MAB94441) or phage diluted in the BSA 1\%-PBS was added to relevant wells. The plate was incubated overnight at $4{ }^{\circ} \mathrm{C}$ and followed by 3 consecutive washes with $150 \mu \mathrm{L}$ PBS-T. The plate was incubated overnight at $4{ }^{\circ} \mathrm{C}$ with $50 \mu \mathrm{L}$ of the anti-M13 antibody (Sino Biological, 11973 MM05T-H) at $0.4 \mu \mathrm{g} / \mathrm{mL}$, or Ab anti-mouse IgG-HRP. Three consecutive washes were performed with $150 \mu \mathrm{L}$ PBS-T. Then $50 \mu \mathrm{L}$ of 1 -Step Ultra TMB solution (Thermo Scientific, 34028) was added to develop the chromogenic signal. The reaction was stopped with $0.5 \mathrm{M}$ sulphuric acid, and optical density (OD) was measured at $450 \mathrm{~nm}$ (measurement wavelength) using the microplate reader (BioRad xMark ${ }^{\mathrm{TM}}$ Microplate Absorbance Spectrophotometer). Significance ( $p$ value) determined for rNS1 recognition against BSA were assessed appropriate arithmetic averaging. Detection of rNS1 with a p-value below 0.05 were considered differentially recognised by peptide-display phages.

\section{- Ethical approval statement.}

The Central Laboratory of Epidemiology, "Centro Médico Nacional La Raza" from the Mexican Institute of Social Security (IMSS), provided all human sera used in this study, with ethical approval by National Scientific Research Committee from Mexican Social Security Institute No. R2018-785-012. This study runs under the ethical guidelines of the Official Mexican Law for Health (NOM-012-SSA3-2012). All participants signed written informed consent. All sera were confirmed for DENV, ZIKV, or CHIKV by RT-PCR.

\section{- Reactivity of phage-displayed peptides to different serotypes of Dengue virus.}

An ELISA assay for assessing the binding specificity of NS1P3, NS1P6, and NS1P8, against the four DENV serotypes was carried out. RT-PCR validated the positivity of human sera as described before. Three biological replicates were used in this assay. The plate was sensitized with 
$50 \mu \mathrm{L}$ of the phages NS1P3, NSP6, and NSP8 amplified one day before of the assay, incubating the plate overnight at $4{ }^{\circ} \mathrm{C}$. Blocking was performed with $100 \mu \mathrm{L}$ of $3 \% \mathrm{BSA}$ for one hour at $37^{\circ} \mathrm{C}$. Then $50 \mu \mathrm{L}$ of positive serum for each DENV serotype was added at 1: 400 dilution in PBS and, healthy serum was used as a negative control. The plate was incubated for two hours at room temperature. Three washes were carried out with $100 \mu \mathrm{L}$ of PBS-T, with constant agitation for 2 min in each wash. Detection was performed with $50 \mu \mathrm{L}$ of anti-NS1 Ab (R\&D Systems, MAB94441) at $2 \mu \mathrm{g} / \mathrm{mL}$, respectively, incubating $2 \mathrm{~h}$ at room temperature. Three more washes were carried out, and $50 \mu \mathrm{L}$ of antimouse IgG conjugated with HRP in dilution 1:10,000 (Abcam, Ab97023) were added, incubated for one hour at room temperature. Three final washes steps were performed, and $50 \mu \mathrm{L}$ of 1-Step Ultra TMB substrate (Thermo Scientific, 34028) was added. The absorbance signal was measured at $450 \mathrm{~nm}$ after stopping the reaction with $50 \mu \mathrm{L}$ of $0.5 \mathrm{M}$ sulphuric acid.

\section{- Specificity of selected anti-dengue peptides.}

The aim of this study was to isolate linear peptides that bind to the NS1 protein of DENV. For this purpose, an ELISA sandwich assay was designed based on anti-DENV NS1 peptide-display phages NS1P3, NS1P6, and NS1P8 and commercial mAbs, acting as capture and detection elements, respectively. A 96-well plate was coated with the phages NS1P3, NSP6, and NSP8, and incubated overnight at $4{ }^{\circ} \mathrm{C}$. Blocking was performed with $100 \mu \mathrm{L}$ of $3 \% \mathrm{BSA}$ for one hour at $37^{\circ} \mathrm{C}$, then $50 \mu \mathrm{L}$ of each positive serum of DENV, ZIKV, CHIKV, were added and a healthy serum was used as negative control, in 1: 400 dilution in PBS 1X and incubated for $2 \mathrm{~h}$ at room temperature. Three washes were performed with $100 \mu \mathrm{L}$ of PBS-T. The detection was then performed with $50 \mu \mathrm{L}$ of the anti-ZIKV (Fitzgerald, 10-2714) and anti-CHIKV (Fitzgerald, 10-2717) antibodies at $1 \mu \mathrm{g} / \mathrm{mL}$ and anti-NS1 (R\&D Systems, MAB94441) at $2 \mu \mathrm{g} / \mathrm{mL}$ respectively, incubating $2 \mathrm{~h}$ at room temperature. Three washes were performed and $50 \mu \mathrm{L}$ of mouse anti-IgG antibody, conjugated with HRP in 1: 10,000 dilution (Abcam, Ab97023) were added and incubated for $1 \mathrm{~h}$ at room temperature. After washing as described above, $50 \mu \mathrm{L}$ of 1-Step Ultra TMB substrate (Thermo Scientific, 34028) were added. The reaction was stopped with $0.5 \mathrm{M}$ sulfuric acid, and absorbance was measured at $450 \mathrm{~nm}$ in a microplate reader.

\section{- Molecular docking.}

The binding of peptides to DENV-NS1 was explored by molecular docking using two different algorithms implemented by GalexyPepDock and CABS Dock server. GalaxyPepDock is a protein-peptide docking tool based on interaction similarity and energy optimization, using Python ${ }^{37}$ to input the peptide sequence and protein ID PDB: 4OIG (DENV-NS1). Default settings were selected. Furthermore, CABS-Dock was used to confirm the analysis. This server is based on a global docking procedure that includes explicit, fully flexible docking simulation and then clustering-based scoring. We selected the CABS-dock simulation runs 10,000 alternative models of the complex, models were ranked and numbered according to their occurrence in docking trajectory $(1=$ most probable result), and ten top-ranked models were reconstructed to allatom representation ${ }^{38}$. The best model was selected for each peptide's complex, and pairs of protein/peptide residues closer than $3 \AA$ were evaluated.

The differences in recognizing between DENV rNS1 protein and BSA used as a negative control by each peptide-display phage were assessed by one-way ANOVA followed by Turkey's multiple comparison test, the detection of rNS1 with a p-value below 0.001 was considered with a significant statistical difference in recognition.

One-way ANOVA was used followed by a Dunnett's test to compare the recognition of each serotype and healthy serum, the significance (pvalue) determined by each DENV serotype was assessed with appropriate arithmetic averaging. Detection of DENV serotype with a p-value below 0.001 was considered differentially recognised for each phage clone. Also, to compare the recognition of the different DENV serotypes a Turkey's test was used, and detection of DENV serotype with a p-value below 0.05 was considered with a significant statistical difference in recognition for each phage clone.

Reactivity of isolated phage clones was assessed against DENV, ZIKV, and CHIKV in serum. To compare ZIKV and CHIKV recognition versus DENV recognition a One-Way ANOVA was performed followed by Turkey's multiple comparison test, where the detection of DENV serotype with a p-value below 0.01 was considered with a significant statistical difference. GraphPad Prism software (version 5.03) was used for performing statistical analyses. The number of replicates per experiment is indicated in each figure legend.

\section{Declarations}

\section{Competing interests:}

The authors declare no competing interests. 


\section{Funding:}

This research was financially supported with funds provided by the Fondo de Cooperación Internacional en Ciencia y Tecnología CONACYTBMBF 2016 Grant: FONCICYT-291205.

\section{Author Contributions:}

Conceptualization: M.B.F., T.A.C.V., D.E.E.Q. Investigation: M.B.F. T.A.C.V., P.H.L.F. Methodology: M.B.F., T.A.C.V., D.E.E.Q. Formal analysis: M.B.F., T.A.C.V., P.H.L.F., D.E.E.Q. Funding acquisition: D.E.E.Q. Project administration: D.E.E.Q. Validation: M.B.F., T.A.C.V., D.E.E.Q. Writing - review \& editing: M.B.F, T.A.C.V, D.E.E.Q, A.G.O, J.E.M.M. All authors have read and approved the final manuscript. T.A.C.V. and D.E.E.Q shares the corresponding authorship.

\section{Acknowledgement:}

Burciaga-Flores Mirna acknowledges the Ph.D. fellowship from CONACYT.

\section{References}

1. Jing, Q. \& Wang, M. Dengue epidemiology. Global Health Journa/3, 37-45, doi:https://doi.org/10.1016/j.glohj.2019.06.002 (2019).

2. Rockstroh, A. et al. Specific detection of dengue and Zika virus antibodies using envelope proteins with mutations in the conserved fusion loop. Emerg Microbes Infect6, e99, doi:10.1038/emi.2017.87 (2017).

3. Lebani, K. et al. Isolation of serotype-specific antibodies against dengue virus non-structural protein 1 using phage display and application in a multiplexed serotyping assay. PLoS One12, e0180669, doi:10.1371/journal.pone.0180669 (2017).

4. Kalayanarooj, S. Clinical Manifestations and Management of Dengue/DHF/DSS. Trop Med Health39, 83-87, doi:10.2149/tmh.2011-S10 (2011).

5. Rajapakse, S. Dengue shock. J Emerg Trauma Shock4, 120-127, doi:10.4103/0974-2700.76835 (2011).

6. Restrepo, B. N. et al. Frequency and clinical manifestations of dengue in urban medellin, Colombia. J Trop Med2014, 872608, doi:10.1155/2014/872608 (2014).

7. Weaver, S. C., Charlier, C., Vasilakis, N. \& Lecuit, M. Zika, Chikungunya, and Other Emerging Vector-Borne Viral Diseases. Annu Rev Med69, 395-408, doi:10.1146/annurev-med-050715-105122 (2018).

8. Zainuddin, A. A., Nordin, A. N. \& Ab Rahim, R. Recent Trends in dengue detection methods using biosensors. IIUM Engineering Journa/19, 134 -153, doi:10.31436/iiumej.v19i2.931 (2018).

9. Ambrose, J. H., Sekaran, S. D. \& Azizan, A. Dengue Virus NS1 Protein as a Diagnostic Marker: Commercially Available ELISA and Comparison to qRT-PCR and Serological Diagnostic Assays Currently Used by the State of Florida. J Trop Med2017, 8072491, doi:10.1155/2017/8072491 (2017).

10. Glasner, D. R., Puerta-Guardo, H., Beatty, P. R. \& Harris, E. The Good, the Bad, and the Shocking: The Multiple Roles of Dengue Virus Nonstructural Protein 1 in Protection and Pathogenesis. Annu Rev Viro/5, 227-253, doi:10.1146/annurev-virology-101416-041848 (2018).

11. Rastogi, M., Sharma, N. \& Singh, S. K. Flavivirus NS1: a multifaceted enigmatic viral protein. Virol J13, 131, doi:10.1186/s12985-016-05907 (2016).

12. Raafat, N., Blacksell, S. D. \& Maude, R. J. A review of dengue diagnostics and implications for surveillance and control. Trans $R$ Soc Trop Med Hyg113, 653-660, doi:10.1093/trstmh/trz068 (2019).

13. Singh, S., Nair, A., Alam, M. \& Mukherjee, B. Outcomes of lacrimal gland injection of botulinum toxin in functional versus nonfunctional epiphora. Journal of Health Research and Reviews4, 104-107, doi:10.4103/ojo.0JO_52_2018 (2017).

14. Mahmuda A et al. Monoclonal antibodies in immunodiagnostic assays: a review of recent applications. Sokoto Journal of Veterinary Sciences15 (2017).

15. Fatima, A. et al. Development of VHH antibodies against dengue virus type 2 NS1 and comparison with monoclonal antibodies for use in immunological diagnosis. PLoS One9, e95263, doi:10.1371/journal.pone.0095263 (2014).

16. Goodchild, S. A. et al. Isolation and characterisation of Ebolavirus-specific recombinant antibody fragments from murine and shark immune libraries. Mol Immuno/48, 2027-2037, doi:10.1016/j.molimm.2011.06.437 (2011).

17. Nuttall, S. D. et al. Selection and affinity maturation of IgNAR variable domains targeting Plasmodium falciparum AMA1. Proteins55, 187197, doi:10.1002/prot.20005 (2004). 
18. Poungpair, O. et al. Generation of human single-chain variable fragment antibodies specific to dengue virus non-structural protein 1 that interfere with the virus infectious cycle. MAbs6, 474-482, doi:10.4161/mabs.27874 (2014).

19. Peltomaa, R., Benito-Pena, E., Barderas, R. \& Moreno-Bondi, M. C. Phage Display in the Quest for New Selective Recognition Elements for Biosensors. ACS Omega4, 11569-11580, doi:10.1021/acsomega.9b01206 (2019).

20. Kim, J. H. et al. Development of peptide biosensor for the detection of dengue fever biomarker, nonstructural 1. PLoS One14, e0222144, doi:10.1371/journal.pone.0222144 (2019).

21. Lim, J. M. et al. An electrochemical peptide sensor for detection of dengue fever biomarker NS1. Anal Chim Acta1026, 109-116, doi:10.1016/j.aca.2018.04.005 (2018).

22. Muller, D. A. \& Young, P. R. The flavivirus NS1 protein: molecular and structural biology, immunology, role in pathogenesis and application as a diagnostic biomarker. Antiviral Res98, 192-208, doi:10.1016/j.antiviral.2013.03.008 (2013).

23. de la Guardia, C., Quijada, M. \& Lleonart, R. Phage-Displayed Peptides Selected to Bind Envelope Glycoprotein Show Antiviral Activity against Dengue Virus Serotype 2. Adv Viro/2017, 1827341, doi:10.1155/2017/1827341 (2017).

24. Chew, M. F., Tham, H. W., Rajik, M. \& Sharifah, S. H. Anti-dengue virus serotype 2 activity and mode of action of a novel peptide. J App/ Microbio/119, 1170-1180, doi:10.1111/jam.12921 (2015).

25. Panya, A., Bangphoomi, K., Choowongkomon, K. \& Yenchitsomanus, P. T. Peptide inhibitors against dengue virus infection. Chem Biol Drug Des84, 148-157, doi:10.1111/cbdd.12309 (2014).

26. Shriver-Lake, L. C. et al. Selection and Characterization of Anti-Dengue NS1 Single Domain Antibodies. Sci Rep8, 18086, doi:10.1038/s41598-018-35923-1 (2018).

27. Andreata-Santos, R. et al. Specificity of NS1-based immunochromatographic tests for dengue virus with regard to the Zika virus protein. Int J Infect Dis95, 276-278, doi:10.1016/j.ijid.2020.04.012 (2020).

28. Wen, J. \& Shresta, S. Antigenic cross-reactivity between Zika and dengue viruses: is it time to develop a universal vaccine? Curr Opin Immuno/59, 1-8, doi:10.1016/j.coi.2019.02.001 (2019).

29. Rocha, L. B. et al. Epitope Sequences in Dengue Virus NS1 Protein Identified by Monoclonal Antibodies. Antibodies (Basel)6, doi:10.3390/antib6040014 (2017).

30. Omokoko, M. D. et al. A highly conserved region between amino acids 221 and 266 of dengue virus non-structural protein 1 is a major epitope region in infected patients. The American journal of tropical medicine and hygiene91, 146-155, doi:10.4269/ajtmh.13-0624 (2014).

31. Songprakhon, P. et al. Peptides targeting dengue viral nonstructural protein 1 inhibit dengue virus production. Sci Rep10, 12933, doi:10.1038/s41598-020-69515-9 (2020).

32. Gelanew, T. \& Hunsperger, E. Development and characterization of serotype-specific monoclonal antibodies against the dengue virus-4 (DENV-4) non-structural protein (NS1). Virol J15, 30, doi:10.1186/s12985-018-0925-7 (2018).

33. Raftery, L. J. et al. Retooling phage display with electrohydrodynamic nanomixing and nanopore sequencing. Lab Chip19, 4083-4092, doi:10.1039/c9lc00978g (2019).

34. Tang, Y. L. et al. Generation and Characterization of Antinonstructural Protein 1 Monoclonal Antibodies and Development of Diagnostics for Dengue Virus Serotype 2. Am J Trop Med Hyg97, 1049-1061, doi:10.4269/ajtmh.17-0003 (2017).

35. Gasteiger, E. et al. ExPASy: The proteomics server for in-depth protein knowledge and analysis. Nucleic Acids Res31, 3784-3788, doi:10.1093/nar/gkg563 (2003).

36. Jr, F. T. C. \& Badani, H. PepDraw: a tool to predict primary structure and calculate theorical properties., <http://www.tulane.edu/ biochem/WW/PepDraw/> (2011).

37. Lee, H., Heo, L., Lee, M. S. \& Seok, C. GalaxyPepDock: a protein-peptide docking tool based on interaction similarity and energy optimization. Nucleic Acids Res43, W431-435, doi:10.1093/nar/gkv495 (2015).

38. Kurcinski, M. et al. A protocol for CABS-dock protein-peptide docking driven by side-chain contact information. Biomed Eng Online16, 73, doi:10.1186/s12938-017-0363-6 (2017).

39. Axelrod, T., Eltzov, E. \& Marks, R. S. Capture-Layer Lateral Flow Immunoassay: A New Platform Validated in the Detection and Quantification of Dengue NS1. ACS Omega5, 10433-10440, doi:10.1021/acsomega.0c00367 (2020).

40. Omar, N. A. S. et al. Sensitive Detection of Dengue Virus Type 2 E-Proteins Signals Using Self-Assembled Monolayers/Reduced Graphene Oxide-PAMAM Dendrimer Thin Film-SPR Optical Sensor. Sci Rep10, 2374, doi:10.1038/s41598-020-59388-3 (2020).

41. Chowdhury, A. D. et al. The detection and identification of dengue virus serotypes with quantum dot and AuNP regulated localized surface plasmon resonance. Nanoscale Advances2, 699-709, doi:10.1039/C9NA00763F (2020).

42. Mehta, R. et al. The neurological complications of chikungunya virus: A systematic review. Rev Med Viro/28, e1978, doi:10.1002/rmv.1978 (2018). 
43. Kumar, S., Bhushan, P., Krishna, V. \& Bhattacharya, S. Tapered lateral flow immunoassay based point-of-care diagnostic device for ultrasensitive colorimetric detection of dengue NS1. Biomicrofluidics12, 034104, doi:10.1063/1.5035113 (2018).

44. Yaren, O. et al. Multiplexed Isothermal Amplification Based Diagnostic Platform to Detect Zika, Chikungunya, and Dengue 1. $J$ Vis Exp, doi:10.3791/57051 (2018).

45. Bosch, I. et al. Rapid antigen tests for dengue virus serotypes and Zika virus in patient serum. Sci Trans/ Med9, doi:10.1126/scitranslmed.aan1589 (2017).

46. Sinawang, P. D., Rai, V., lonescu, R. E. \& Marks, R. S. Electrochemical lateral flow immunosensor for detection and quantification of dengue NS1 protein. Biosens Bioelectron77, 400-408, doi:10.1016/j.bios.2015.09.048 (2016).

47. Jahanshahi, P. et al. Kinetic analysis of IgM monoclonal antibodies for determination of dengue sample concentration using SPR technique. Bioengineered8, 239-247, doi:10.1080/21655979.2016.1223413 (2017).

48. Cecchetto, J. et al. An impedimetric biosensor to test neat serum for dengue diagnosis. Sensors and Actuators B-chemica/213, 150-154 (2015).

49. Jahanshahi, P., Zalnezhad, E., Sekaran, S. D. \& Adikan, F. R. Rapid immunoglobulin M-based dengue diagnostic test using surface plasmon resonance biosensor. Sci Rep4, 3851, doi:10.1038/srep03851 (2014).

\section{Table}

Due to technical limitations, table 2 is only available as a download in the Supplemental Files section.

\section{Figures}

\section{Phage title}

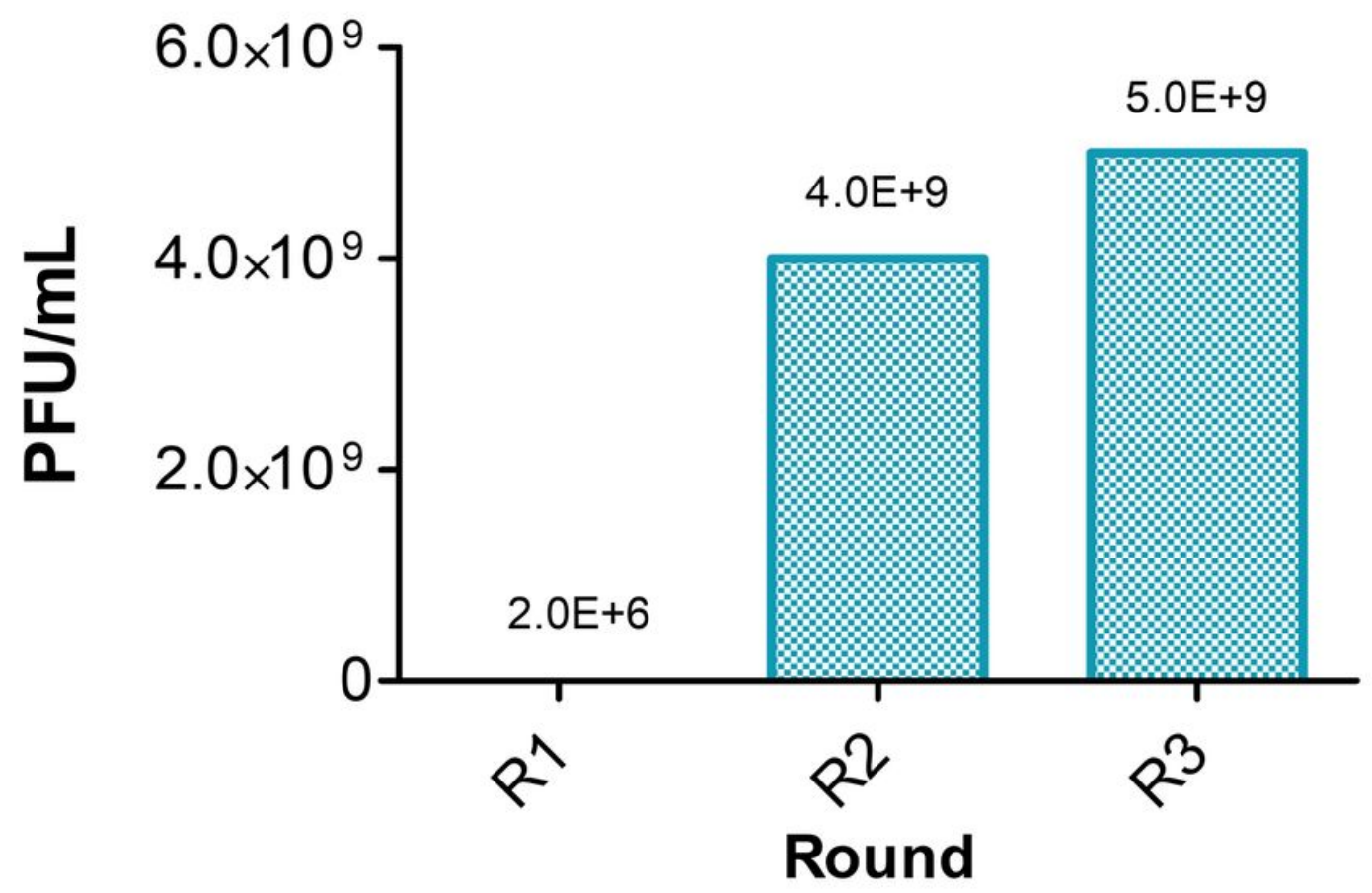

Figure 1

Recognition increases during the panning. The phage pool with peptide-display phages from the Trico-20 library against rNS1 increases recognition level during the third rounds of panning. 
A

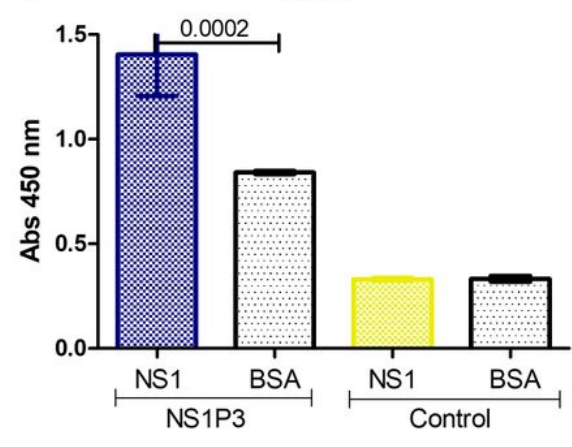

B
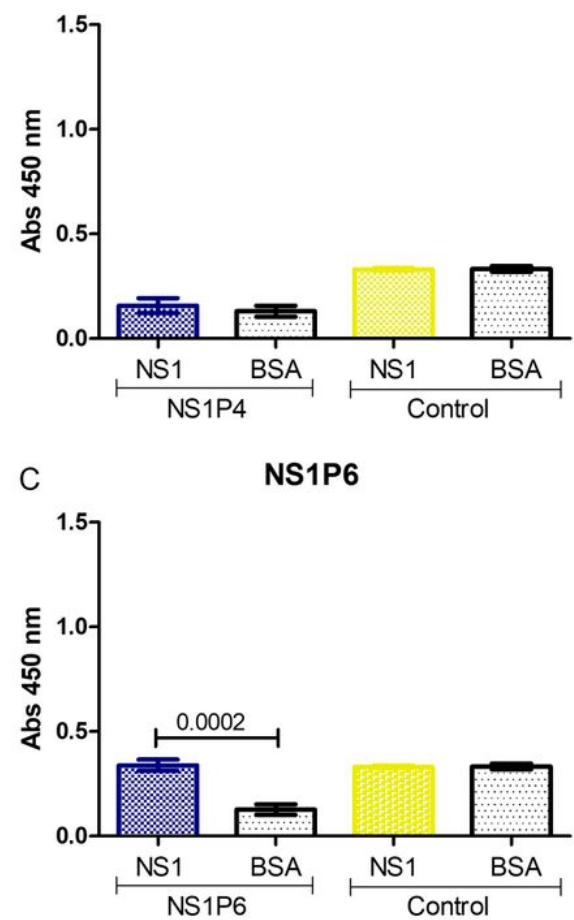

D NS1P8

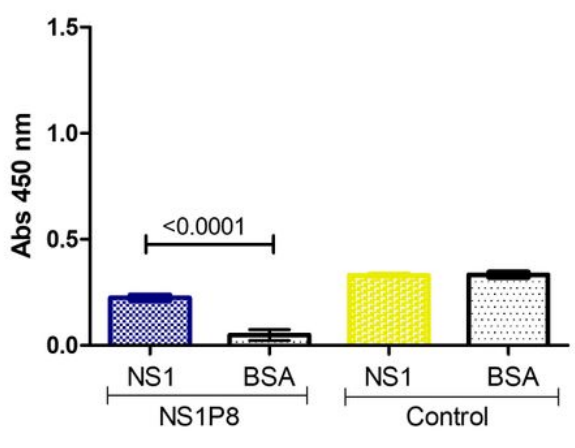

E

NS1P9

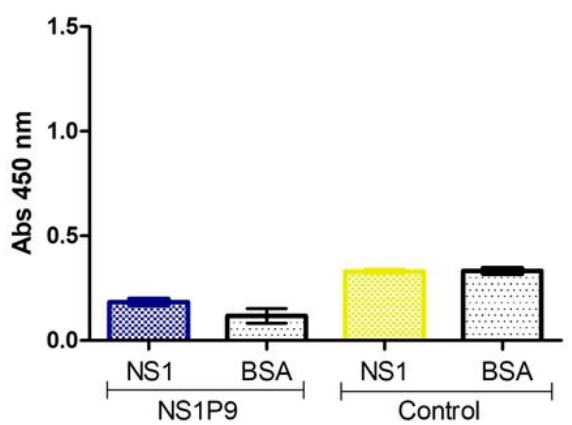

F

NS1P14

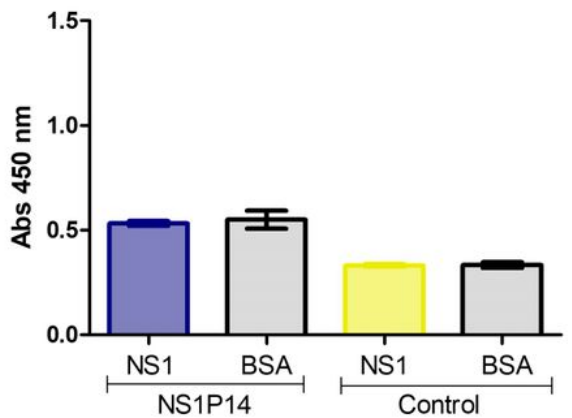

Figure 2

Recognizing ELISA assay, DENV rNS1 protein was used as an antigen. (A) NS1P3 peptide-display phage, (B) NS1P4 peptide-display phage, (C) NS1P6 peptide-display phage, (D) NS1P8 peptide-display phage, (E) NS1P9 peptide-display phage, and (F) NS1P14 peptide-display phage. Only NS1P3, NS1P6, and NS1P8 peptide-display phages recognised the rNS1 protein when are compared with BSA as a negative control. Error bars represent standard deviations of the mean from three biological replicates. One-way ANOVA followed by Turkey's multiple comparison test. Brackets encompass the comparisons for which statistically significant $p$ values are shown on top of the bars depicting the means. 
A

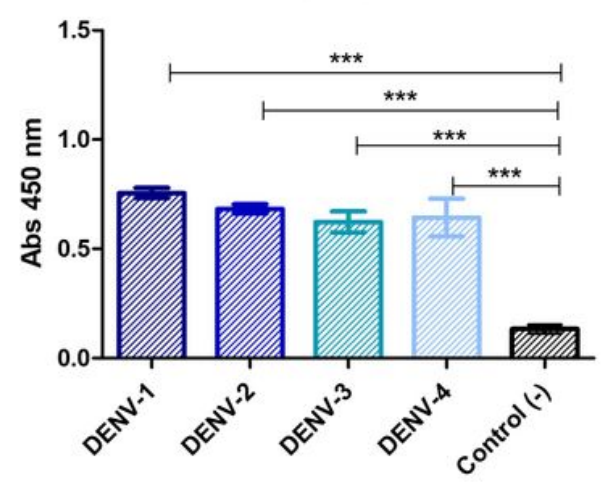

B

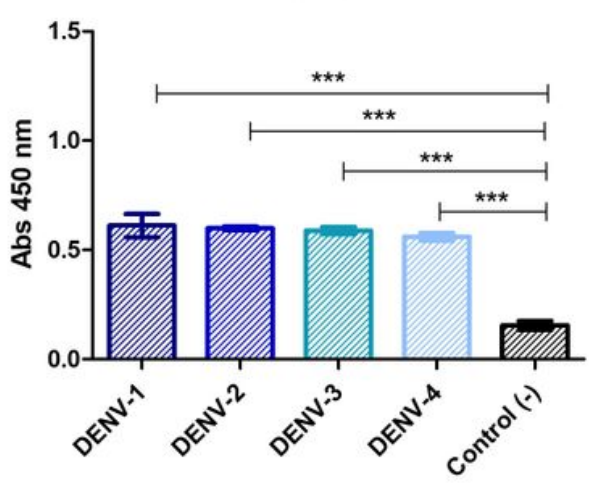

*** $p<0.0001$
C

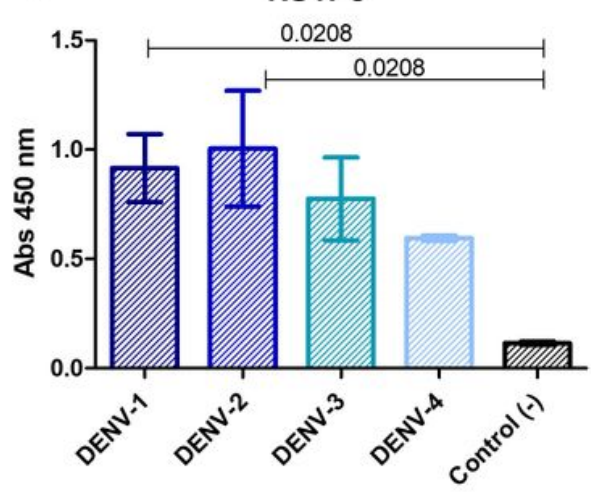

Figure 3

Reactivity of isolated phage clones against native NS1 from all DENV serotypes in serum. (A) NS1P3 peptide-display phage, (B) NS1P6 peptide-display phage, and (C) NS1P8 peptide-display phage. All three peptide-display phages recognise the NS1 from all four serotypes of DENV present in serum samples when it was compared with healthy serum as a negative control. Data were normalized for analysis. Error bars represent standard deviations of the mean from three biological replicates. One-Way ANOVA followed by Dunnett's test was used to assess the significance of changes in recognizing between each DENV serotype and healthy serum as a negative control by each peptide-display phage. Brackets encompass the comparisons for which statistically significant $p$ values are shown on top of the bars depicting the means.
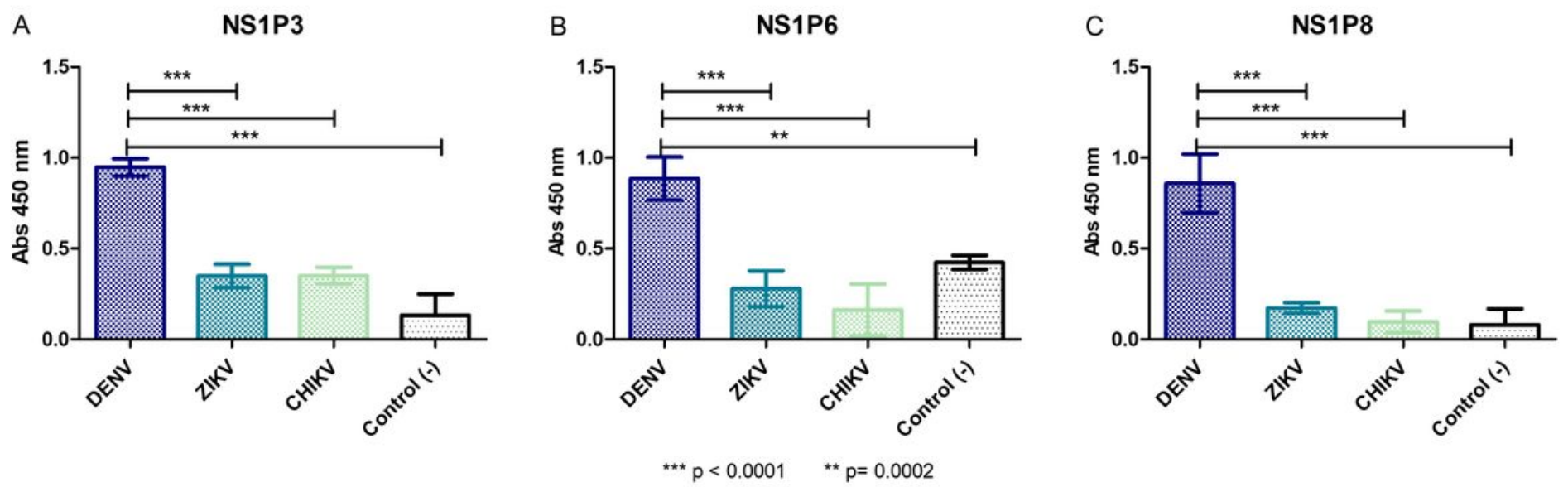

\section{Figure 4}

Cross-recognition ELISA assay. (A) Clone of phage NS1P3 against DENV, ZIKV, and CHIKV, (B) Clone of phage NS1P6 against DENV, ZIKV, and CHIKV, and (C) Clone of phage NS1P8 against DENV, ZIKV, and CHIKV. Data were normalized for analysis. Error bars represent standard deviations of the mean from three biological replicates. One-way ANOVA followed by Turkey's multiple comparison test. Brackets encompass the comparisons for which statistically significant $p$ values are shown on top of the bars depicting the means. 

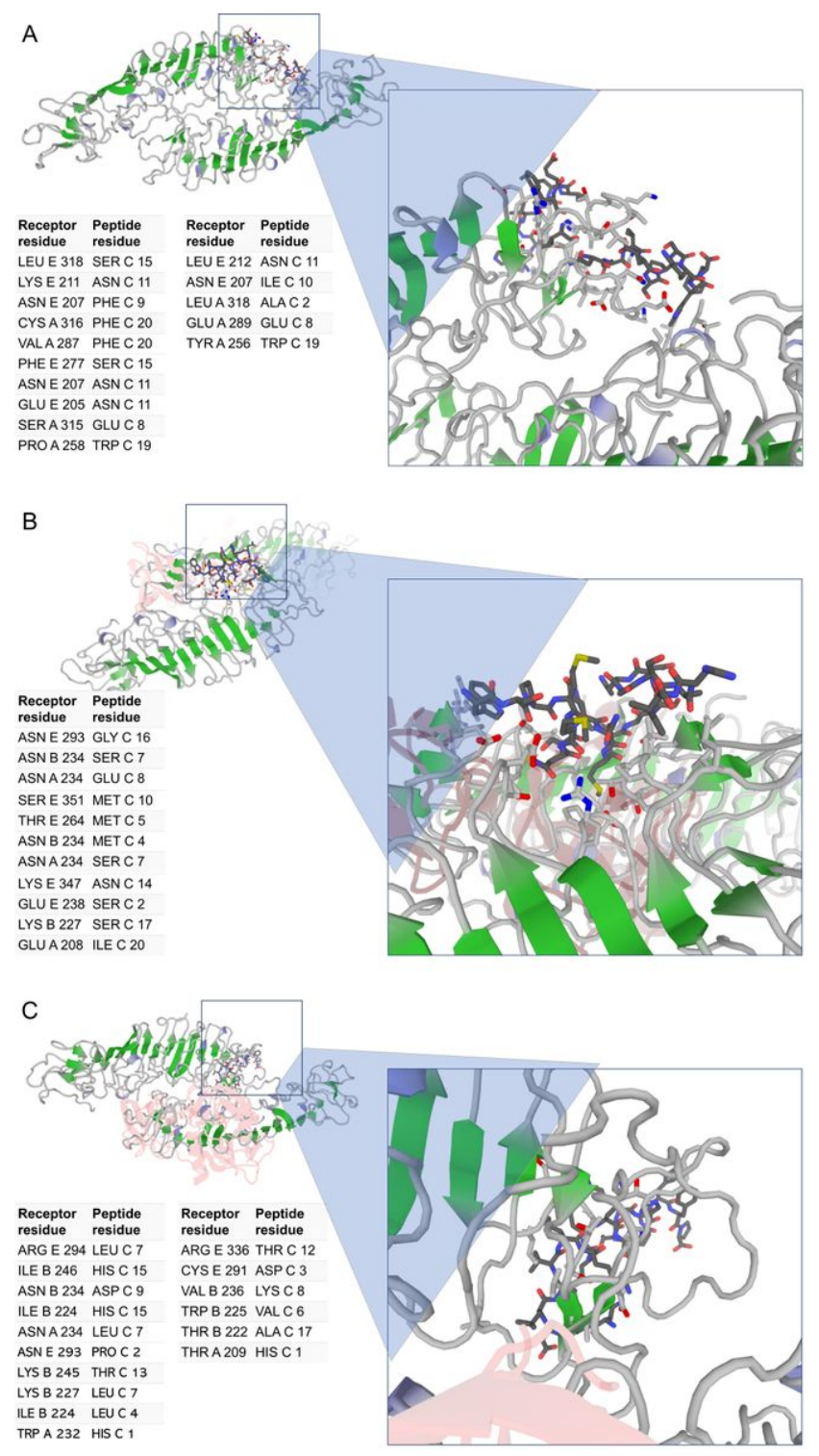

Figure 5

Representation of NS1 protein residues with NSP3, NS1P6, and NS1P8 peptides, respectively, obtained from molecular docking performed in the GalaxyPepDock, confirmed by CABS-Dock. A) NS1P3 peptide B) NS1P6 peptide, and C) NS1P8 peptide.

\section{Supplementary Files}

This is a list of supplementary files associated with this preprint. Click to download.

- Table2.Peptidesequences.docx 